\title{
Effect of hydrogen dilution on carrier transport in hydrogenated boron-doped nanocrystalline silicon-silicon carbide alloys
}

\author{
Seung Yeop Myong a) and Koeng Su Lim \\ Department of Electrical Engineering and Computer Science, Korea Advanced Institute of Science \\ and Technology, 373-1 Guseong-dong, Yuseong-gu, Daejeon 305-701 Republic of Korea \\ Makoto Konagai \\ Department of Physical Electronics, Tokyo Institute of Technology, 2-12-1 O-okayama, Meguro-ku, \\ Tokyo 152-8552 Japan
}

(Received 3 October 2005; accepted 18 January 2006; published online 10 March 2006)

\begin{abstract}
The effect of the hydrogen dilution ratio on characteristics of hydrogenated boron-doped nanocrystalline silicon-silicon carbide alloy $(p-\mathrm{nc}-\mathrm{Si}-\mathrm{SiC}: \mathrm{H})$ films is investigated. Hydrogen coverage near the growing surface causes nanocrystallization by retarding the reactions of the precursors. It was found that $p-\mathrm{nc}-\mathrm{Si}-\mathrm{SiC}: \mathrm{H}$ alloys have two different kinds of carrier transport mechanisms: one is the thermally activated hopping conduction between neighboring crystallites near room temperature and the other is the band tail hopping conduction below $150 \mathrm{~K}$. However, the film at the onset of the nanocrystalline growth exhibits a different behavior due to a large band tail disorder. (C) 2006 American Institute of Physics. [DOI: 10.1063/1.2177641]
\end{abstract}

To improve the $p / i$ interface of thin-film silicon $(\mathrm{Si})$ solar cells, we proposed an inhomogeneous hydrogenated boron (B)-doped nanocrystalline silicon-silicon carbide ( $p$ nc-Si-SiC:H) alloy films. This material contains nc-Si grains embedded in a hydrogenated amorphous silicon carbide $(a-\mathrm{SiC}: \mathrm{H})$ matrix via a mercury $(\mathrm{Hg})$-sensitized photoassisted chemical-vapor deposition (photo-CVD) technique, combining the photodecomposition of ethylene $\left(\mathrm{C}_{2} \mathrm{H}_{4}\right)$ and hydrogen $\left(\mathrm{H}_{2}\right)$ dilution. ${ }^{1}$ As the photo-CVD technique is iondamage-free due to its mild process [the intensity of ultraviolet (UV) light irradiation: $\left.\sim 10 \mathrm{~mW} / \mathrm{cm}^{2}\right]$, ${ }^{1}$ the fabricated mixed-phase alloys are highly conductive and transparent. ${ }^{2,3}$ Therefore, the possibility of $p$-nc-Si-SiC:H alloy films as window layers of thin-film Si solar cells was confirmed. ${ }^{4}$ Based on the deposition of the $p$-nc-Si-SiC:H alloys, $\mathrm{H}_{2}$-diluted $p$ - $a$-SiC: $\mathrm{H}$ buffer layers of pin-type amorphous silicon $(a-\mathrm{Si}: \mathrm{H})$ and protocrystalline silicon (pc-Si:H) multilayer solar cells were prepared. ${ }^{5-8}$ Accordingly, a dramatic improvement of all solar cell parameters was achieved by effectively reducing the recombination loss at the $p / i$ interface. However, a more detailed study is required on the nature of the mixed-phase $p$-nc-Si-SiC: $\mathrm{H}$ alloy films that would have the best deposition conditions for photovoltaic application. A previous report by the authors introduced the temperature dependence of the direct current (dc) dark conductivity $\left(\sigma_{D}\right)$ of $p$-nc-Si-SiC:H alloy films prepared with a different $\mathrm{B}$ doping ratio [diborane/silane $\left.\left(\mathrm{B}_{2} \mathrm{H}_{6} / \mathrm{SiH}_{4}\right)\right] .{ }^{9}$ In this study, we investigate the effect of the $\mathrm{H}_{2}$ dilution on the structural and carrier transport characteristics of the $p$-nc$\mathrm{Si}-\mathrm{SiC}: \mathrm{H}$ alloy films.

The films were deposited by the $\mathrm{Hg}$-sensitized photoCVD technique using a mixture of $\mathrm{SiH}_{4}, \mathrm{H}_{2}, \mathrm{~B}_{2} \mathrm{H}_{6}$, and $\mathrm{C}_{2} \mathrm{H}_{4}$ reactant gases. A low-pressure $\mathrm{Hg}$ lamp with resonance lines of 184.9 and $253.7 \mathrm{~nm}$ was used as an UV light source to dissociate the mixture gases. In all depositions, the $\mathrm{B}_{2} \mathrm{H}_{6} / \mathrm{SiH}_{4}$ value, ethylene gas flow ratio $\left(\mathrm{C}_{2} \mathrm{H}_{4} / \mathrm{SiH}_{4}\right)$, chamber pressure, substrate temperature, and $\mathrm{Hg}$ bath temperature were kept at $1000 \mathrm{ppm}, 0.07,0.46 \mathrm{Torr}$, at $250{ }^{\circ} \mathrm{C}$,

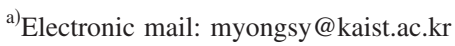

and $20^{\circ} \mathrm{C}$, respectively. The values of $\mathrm{B}_{2} \mathrm{H}_{6} / \mathrm{SiH}_{4}$ and $\mathrm{C}_{2} \mathrm{H}_{4} / \mathrm{SiH}_{4}$ were the same as the values of the optimum deposition condition for the $\mathrm{H}_{2}$-diluted $p$ - $a$-SiC: $\mathrm{H}$ buffer layers of the solar cells. ${ }^{5-8}$ Approximately $150 \mathrm{~nm}$ thick films were deposited on Corning 7059 glass substrates with a varying hydrogen dilution ratio $\left(\mathrm{H}_{2} / \mathrm{SiH}_{4}\right)$. The deposition rate of the films gradually decreased from 1.9 to $1.0 \mathrm{~nm} / \mathrm{min}$ with the increase in $\mathrm{H}_{2} / \mathrm{SiH}_{4}$ from 15 to 30 .

To inspect the structural change, we measured the selected-area transmission electron diffraction (SAED) images of the films. We also performed Raman spectroscopy (JASCO Corp., NRS-1000 system) using an Ar laser with a wavelength of $532 \mathrm{~nm}$. The Raman collection depth at this wavelength is $\sim 50 \mathrm{~nm}$ for $a-\mathrm{Si}: \mathrm{H}$ and $120-170 \mathrm{~nm}$ for the hydrogenated microcrystalline silicon $(\mu c-\mathrm{Si}: \mathrm{H}) .{ }^{10}$ The details for the $\sigma_{D}$ measurements were introduced in a previous report. $^{9}$

Figure 1 shows the SAED images of the $p$-nc$\mathrm{Si}-\mathrm{SiC}: \mathrm{H}$ alloy films prepared with different $\mathrm{H}_{2} / \mathrm{SiH}_{4}$. In

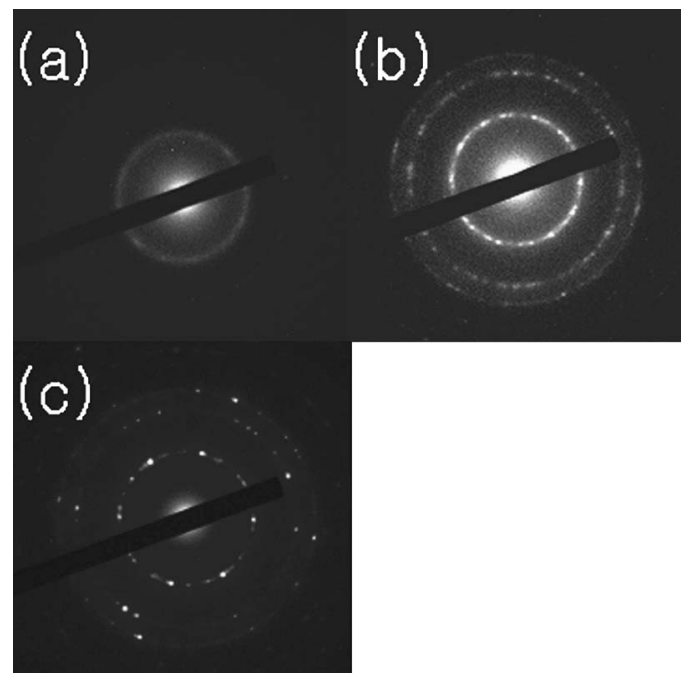

FIG. 1. SAED images of the $p$-nc-Si-SiC:H alloy films prepared at different $\mathrm{H}_{2} / \mathrm{SiH}_{4}$ conditions: (a) $\mathrm{H}_{2} / \mathrm{SiH}_{4}=15$, (b) $\mathrm{H}_{2} / \mathrm{SiH}_{4}=20$, and (c) $\mathrm{H}_{2} / \mathrm{SiH}_{4}=25$. 


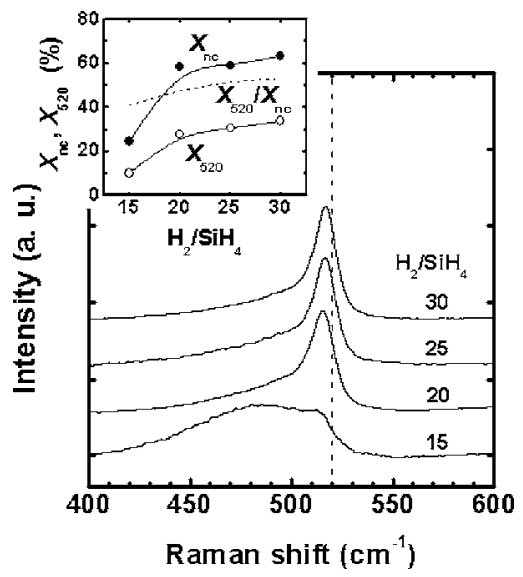

FIG. 2. Raman spectra of the $p$-nc-Si-SiC:H alloy films. The inset graph shows the crystal volume fractions of the films.

the case of $\mathrm{H}_{2} / \mathrm{SiH}_{4}=15$, three dim rings were detected from the center corresponding to planes (111), (220), and (311) of crystalline $\mathrm{Si}(c-\mathrm{Si})$. In the case of $\mathrm{H}_{2} / \mathrm{SiH}_{4}=20$, bright spots on the three broad rings were detected. With a further increase in $\mathrm{H}_{2} / \mathrm{SiH}_{4}$, the SAED image shows bright spots on the three sharp rings, which indicate highly oriented $c$-Si growth in the film.

Figure 2 displays the results of the Raman spectroscopy of the $p$-nc-Si-SiC:H alloy films. The deconvolution of each spectrum in Fig. 2 shows three independent peaks: (i) a transverse optical (TO) mode of the nc-Si component near $520 \mathrm{~cm}^{-1}$, (ii) an intermediate fraction near $510 \mathrm{~cm}^{-1}$ due to small crystallites and a defective part of the crystalline phase, ${ }^{10}$ and (iii) a TO-like $a$-Si:H phase near $480 \mathrm{~cm}^{-1}$, which is related to the $\mathrm{Si}-\mathrm{Si}$ bonds in $a-\mathrm{SiC}: \mathrm{H}$. No Raman peak associated with a crystalline silicon carbide $(c-\mathrm{SiC})$ phase was observed in the range of $750-950 \mathrm{~cm}^{-1}$. However, a Fourier transform infrared (FTIR) spectrum exhibits very small local vibrational modes of $\mathrm{SiC}$ at $\sim 657$ and $\sim 789 \mathrm{~cm}^{-1}$, which confirm the formation of SiC. ${ }^{1}$ These films possess approximately $1-2$ at. $\% \mathrm{C}$, which was roughly determined from the Auger results. ${ }^{1}$ From the data, it is possible to conclude that the film consists of nc-Si grains embedded in an $a$-SiC: $\mathrm{H}$ matrix. The increase in $\mathrm{H}_{2} / \mathrm{SiH}_{4}$ induces the nanocrystalline growth by suppressing the broad $a-\mathrm{SiC}: \mathrm{H}$ peak. The average grain size $(L)$ of the films is estimated using a deviation $(\Delta \omega)$ of the nc-Si TO peak from the frequency of the $c$-Si To peak $\left(520 \mathrm{~cm}^{-1}\right) ;^{11} L$ $=2 \pi(2 / \Delta \omega)^{1 / 2}$. With the increase in $\mathrm{H}_{2} / \mathrm{SiH}_{4}$, the $L$ value increases from 3.8 to $5.7 \mathrm{~nm}$.

The degree of crystallinity is indicated by the crystal volume fraction $\left(X_{\mathrm{nc}}\right)$. In addition, the $X_{520}$ value is evaluated in order to monitor the dominant crystal component. Since $L$ of all the films is only $3-6 \mathrm{~nm}, X_{\mathrm{nc}}$, i.e., $X_{\mathrm{nc}}=\left(I_{510}\right.$ $\left.+I_{520}\right) /\left(I_{480}+I_{510}+I_{520}\right)$, where $I_{i}$ denotes an integrated intensity at $i \mathrm{~cm}^{-1}$, and $X_{520}$, i.e., $X_{520}=I_{520} /\left(I_{480}+I_{510}+I_{520}\right)$, can be found assuming the Raman cross-section ratio to be 1 . As shown in the inset graph of Fig. 2, both the $X_{\mathrm{nc}}$ and $X_{520}$ values are gradually enhanced with the increase in $\mathrm{H}_{2} / \mathrm{SiH}_{4}$. In the case of $\mathrm{H}_{2} / \mathrm{SiH}_{4}=15$, the film shows the onset of the nanocrystalline growth. With an increase in $\mathrm{H}_{2} / \mathrm{SiH}_{4}$ to 20 , $X_{\mathrm{nc}}$ is abruptly elevated. In contrast, with a further increase in $\mathrm{H}_{2} / \mathrm{SiH}_{4}, X_{\mathrm{nc}}$ shows a small increase, and the nc-Si TO peak becomes dominative $\left(X_{520} / X_{\mathrm{nc}} \geqslant 0.5\right)$ due to the forma-

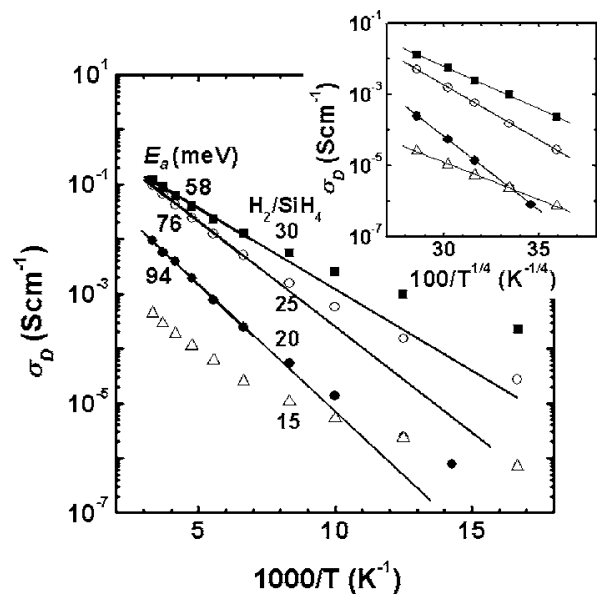

FIG. 3. Arrhenius plot for $\sigma_{D}$ of the $p$-nc-Si-SiC:H films.

tion of large grains $(L \geqslant 5 \mathrm{~nm})$ and the reduction of the defective crystalline phase. ${ }^{10}$

From the results, it is reasonable to assume that the $\mathrm{H}_{2}$ dilution of $\mathrm{SiH}_{4}$ during the film deposition causes hydrogen coverage of the growing film surface. ${ }^{12}$ This process enhances the surface diffusion coefficient of the precursors decomposed by the UV illumination, initiating precursors adsorbed at the growing surface to find their energetically suitable sites. ${ }^{13}$ This results in a retardation of the deposition rate, which decreases the structural disorder in the film by relaxing the $a-\mathrm{SiC}: \mathrm{H}$ matrix, and causes the generation of crystallites.

Figure 3 depicts the temperature $(T)$ dependence of $\sigma_{D}$ for films prepared with different $\mathrm{H}_{2} / \mathrm{SiH}_{4}$. The $\sigma_{D}$ measured at room temperature reveals a gradual increase with the increments of $\mathrm{H}_{2} / \mathrm{SiH}_{4}$, due to the increase in the crystallinity. ${ }^{1}$ The experimental data indicate that the conduction mechanism in the films under consideration is closely related to $X_{\mathrm{nc}}$ influenced by $\mathrm{H}_{2} / \mathrm{SiH}_{4}$. With the exception of the film prepared at $\mathrm{H}_{2} / \mathrm{SiH}_{4}=15$, the different slopes of the experimental curves in the low- and high-temperature regions point to different mechanisms of carrier transport. The straight lines approximating the experimental points for $T>150 \mathrm{~K}$ reveal a thermally activated process, ${ }^{14}$

$$
\sigma_{D}(T)=\sigma_{o} \exp \left(-E_{a} / k T\right),
$$

where $\sigma_{o}$ is the conductivity prefactor, $E_{a}$ is the activation energy, and $k$ is Boltzmann's constant. $E_{a}$ values extracted using Eq. (3) are listed in this figure. It is seen that $E_{a}$ decreases with an increase in $\mathrm{H}_{2} / \mathrm{SiH}_{4}$ due to the formation of highly crystalline and conductive films. In this temperature regime $(T>150 \mathrm{~K})$, we previously reported that $\sigma_{D}$ of the highly crystalline films generally obeyed the Meyer-Neldel rule (MNR), and that carrier transport was dominated not by the extended-states transport (which was the main transport mechanism in conventional $a-\mathrm{Si}: \mathrm{H}$ ), but by thermally activated hopping between neighboring crystallites. ${ }^{9}$ However, the film at the onset of the nanocrystalline growth $\left(\mathrm{H}_{2} / \mathrm{SiH}_{4}=15\right)$ reveals the different transport behavior of a continuous bending in this temperature regime. We attribute the continuous bending with the temperature to a large band tail disorder. ${ }^{15}$

Below $150 \mathrm{~K}$, all of the $p$-nc-Si-SiC:H alloy films display a linear relationship between $\log \sigma_{D}$ and $T^{1 / 4}$, as shown in the inset graph of Fig. 3. This behavior is consistent with license or copyright; see http://apl.aip.org/about/rights_and_permissions 
TABLE I. Values of DOS calculated from the percolation model for the $p$-nc-Si-SiC:H alloy films.

\begin{tabular}{ccccc}
\hline \hline & $\begin{array}{c}\sigma_{o o} \\
\mathrm{H}_{2} / \mathrm{SiH}_{4}\end{array}$ & $\begin{array}{c}T_{0}^{*} \\
\left(\Omega^{-1} \mathrm{~cm}^{-1}\right)\end{array}$ & $\begin{array}{c}G(E)(\mathrm{K}) \\
\left(\mathrm{eV}^{-1} \mathrm{~cm}^{-3}\right)\end{array}$ & $\begin{array}{c}G(E)\left(\mathrm{eV}^{-1} \mathrm{~cm}^{-3}\right) \\
\left(C_{0}=310\right)\end{array}$ \\
\hline 15 & $2.49 \times 10^{1}$ & $2.49 \times 10^{6}$ & $3.37 \times 10^{19}$ & $6.53 \times 10^{20}$ \\
20 & $1.84 \times 10^{8}$ & $8.35 \times 10^{7}$ & $2.22 \times 10^{18}$ & $4.31 \times 10^{19}$ \\
25 & $3.42 \times 10^{6}$ & $2.57 \times 10^{7}$ & $7.23 \times 10^{18}$ & $1.40 \times 10^{20}$ \\
30 & $8.17 \times 10^{4}$ & $8.98 \times 10^{6}$ & $2.07 \times 10^{19}$ & $5.01 \times 10^{20}$ \\
\hline \hline
\end{tabular}

a variable range hopping (VRH) model known to be limited to a low-temperature region. ${ }^{16}$ In this temperature region, $\sigma_{D}$ follows Mott's law, ${ }^{17}$ where the carrier transport is dominated by the VRH hopping process in a constant density of states (DOS) near the Fermi level $\left(E_{F}\right)$,

$$
\sigma_{D}=\sigma_{o o} \exp \left[-\left(T_{0} / T\right)^{1 / 4}\right] \text {. }
$$

In the classical Mott's model, the $\sigma_{o o}$ and $T_{0}$ coefficients are given by

$$
\begin{aligned}
& \sigma_{o o}=e^{2} N\left(E_{F}\right) \gamma_{\mathrm{ph}} / \alpha^{2}, \\
& T_{0}=16 \alpha^{3} / k N\left(E_{F}\right),
\end{aligned}
$$

where $e$ is the electron charge, $\gamma_{\mathrm{ph}}$ is the characteristic phonon frequency, $\alpha$ is the inverse decay length of the wave function of localized states near $E_{F}$, and $N\left(E_{F}\right)$ is the concentration of these localized states at $E_{F}$. However, this model with a constant DOS leads to improbable $N\left(E_{F}\right)$ for disordered thin films with exponential tail state distributions in the gap. ${ }^{18}$ Hence, this model must be corrected to achieve rational $N\left(E_{F}\right)$.

Godet ${ }^{19}$ predicted that using the localization radius as a parameter $\left[10^{-5}<N\left(E_{F}\right) \alpha^{-3}<1\right]$ a single-phonon band tail hopping within an exponential DOS gives a linear relationship between $\ln \sigma_{o o}$ and $T_{0}^{1 / 4}$. Concari et al. ${ }^{20}$ provided the validity of Godet's model for $i-\mu c-\mathrm{Si}: \mathrm{H}$ and $p-\mu c-\mathrm{Si}: \mathrm{H}$ by correlating the classical percolation theory, ${ }^{21}$

$$
T_{0}^{*}=C_{0} \alpha^{3} / k g\left(E_{F}\right),
$$

where $C_{0}$ is a constant with a value in the range of 16 (Ref. 21 ) to 310 (Ref. 19) and $g\left(E_{F}\right)$ is the unitary energy DOS with an exponential distribution near $E_{F}$ in Godet's model. Here, $\alpha^{-1}$ typically varies between 0.3 and $3 \mathrm{~nm}$.

From Eq. (5), it is possible to estimate the $g\left(E_{F}\right)$ value of the $p$-nc-Si-SiC:H alloy films by assuming $\alpha^{-1}$ to be $1 \mathrm{~nm} .^{20,22}$ The calculated parameters are presented in Table I. The film at the onset of the nanocrystalline growth $\left(\mathrm{H}_{2} / \mathrm{SiH}_{4}=15\right)$ has the highest DOS, which supports the assumption of many defects and structural disorder in the film. With the increase in $\mathrm{H}_{2} / \mathrm{SiH}_{4}$ from 15 to 20 , the value of $g\left(E_{F}\right)$ ) for the $p$-nc-Si-SiC:H alloy films is steeply reduced by an order of magnitude. The reduction is ascribed to the decrease in the volume fraction of the $a-\mathrm{SiC}: \mathrm{H}$ matrix. However, with a further increase in $\mathrm{H}_{2} / \mathrm{SiH}_{4}$, the value of $g\left(E_{F}\right)$ for the highly nanocrystalline films gradually increases, due to the enhanced distribution of dangling bond states in the grain boundary regions and the enhanced ionized impurities near $E_{F}$.

On the other hand, Ram et al. ${ }^{15}$ suggested a $T^{-1 / 2}$ dependence on the $\log \sigma_{D}$ of fully crystallize $i$ - $\mu c-\mathrm{Si}: \mathrm{H}$ films in the low-temperature region of $80-300 \mathrm{~K}$. They attributed this behavior to the tunneling of carriers through barriers similar to what is observed in granular metals. Thus, the $T^{-1 / 2}$ dependence on the $\log \sigma_{D}$ of the $p$-nc-Si-SiC:H alloy films was checked at this point in this study. Although the defective film deposited at $\mathrm{H}_{2} / \mathrm{SiH}_{4}=15$ shows a good linear fit near room temperature, this fitting method makes a considerable deviation of all the samples in the very lowtemperature region below $150 \mathrm{~K}$. Therefore, it is concluded that the aforementioned fitting method is better than the method suggested by Ram et al. for the mixed-phased $p$ nc-Si-SiC:H alloy films. The recent finding by Dussan et al., ${ }^{22}$ which presents a very good $T^{-1 / 4}$ dependence on the $\log \sigma_{D}$ of $p$ - $\mu c-\mathrm{Si}: \mathrm{H}$ films in the low-temperature range of 120-300 K, supports our conclusion.

Finally a good linear relationship between $\ln \sigma_{o o}$ and $T_{0}^{* 1 / 4}$ of the $p$-nc-Si-SiC:H alloy films, including data in Ref. 9 is found. Interestingly, the relationship is almost identical to the linear relationship of $i-\mu c-\mathrm{Si}: \mathrm{H}$ and $p-\mu c-\mathrm{Si}: \mathrm{H}^{20}$ This result supports the validity of Godet's model.

In summary, it is found that $\mathrm{H}_{2} / \mathrm{SiH}_{4}$ significantly impacts the level of $E_{F}$ and the DOS formation in the films. From the results of dc $\sigma_{D}$ measured over the temperature range of 60-300 K, two different kinds of the carrier transport mechanisms of the highly crystalline $p$-nc-Si-SiC:H alloy films were observed; the thermally activated mechanism mainly due to intercrystallite hopping near the roomtemperature region, and the band tail hopping mechanism below $150 \mathrm{~K}$. However, the film prepared at the onset of the nanocrystalline growth (with the low $\mathrm{H}_{2} / \mathrm{SiH}_{4}$ value of 15) reveals the continuous bending near room temperature primary due to the large band tail disorder.

${ }^{1}$ S. Y. Myong, H. K. Lee, E. Yoon, and K. S. Lim, J. Non-Cryst. Solids 298, 131 (2002).

${ }^{2}$ S. Y. Myong, O. Shevaleevskiy, S. Miyajima, M. Konagai, and K. S. Lim, J. Non-Cryst. Solids 351, 89 (2005).

${ }^{3}$ H. K. Lee, S. Y. Myong, K. S. Lim, and E. Yoon, J. Non-Cryst. Solids 316, 297 (2003).

${ }^{4}$ S. Y. Myong, T. H. Kim, K. H. Kim, B. T. Ahn, S. Miyajima, M. Konagai, and K. S. Lim, Sol. Energy Mater. Sol. Cells 81, 485 (2004).

${ }^{5}$ S. Y. Myong, S. S. Kim, and K. S. Lim, J. Appl. Phys. 95, 1525 (2004).

${ }^{6}$ S. Y. Myong and K. S. Lim, Appl. Phys. Lett. 86, 033506 (2005).

${ }^{7}$ S. Y. Myong, S. W. Kwon, M. Konagai, and K. S. Lim, Sol. Energy Mater. Sol. Cells 85, 133 (2005).

${ }^{8}$ S. Y. Myong, J. M. Pearce, M. Konagai, and K. S. Lim, Appl. Phys. Lett. 87, 193509 (2005); S. Y. Myong, S. W. Kwon, M. Kondo, M. Konagai, and K. S. Lim, Semicond. Sci. Technol. 21, L11 (2006).

${ }^{9}$ S. Y. Myong, O. Shevaleevskiy, S. Miyajima, M. Konagai, and K. S. Lim, J. Appl. Phys. 98, 054311 (2005).

${ }^{10}$ C. Droz, E. Vallat-Sauvain, J. Bailat, L. Feitknecht, J. Meier, and A. Shah, Sol. Energy Mater. Sol. Cells 81, 61 (2004).

${ }^{11}$ Y. He, C. Yin, G. Cheng, L. Wang, X. Liu, and G. Y. Hu, J. Appl. Phys. 60, 673 (1993).

${ }^{12}$ S. Ghosh, A. De, S. Ray, and A. K. Barua, J. Appl. Phys. 71, 5205 (1992).

${ }^{13}$ A. Matsuda, J. Non-Cryst. Solids 59/60, 767 (1983).

${ }^{14}$ W. Meyer and H. Neldel, Z. Tech. Phys. (Leipzig) 12, 588 (1937).

${ }^{15}$ S. K. Ram, S. Kumar, R. Vanderhaghen, and P. R. i Cabarrocas, J. NonCryst. Solids 299-302, 411 (2002).

${ }^{16}$ N. F. Mott, J. Non-Cryst. Solids 1, 1 (1968).

${ }^{17}$ N. F. Mott, Metal-Insulator Transitions (Taylor \& Francis, London, 1990).

${ }^{18}$ A. Helmbold, P. Hammer, J. U. Thiele, K. Rohwer, and D. Meissner, Philos. Mag. B 72, 335 (1995).

${ }^{19}$ C. Godet, J. Non-Cryst. Solids 299-302, 333 (2002).

${ }^{20}$ S. B. Concari, R. H. Buitrago, M. T. Gutiérrez, and J. J. Gandía, J. Appl. Phys. 94, 2417 (2003).

${ }^{21}$ N. F. Mott and E. A. Davis, Electronic Processes in Non-Crystalline Materials, 2nd ed. (Oxford University Press, Oxford, 1979).

${ }^{22}$ A. Dussan and R. H. Buitirago, J. Appl. Phys. 97, 043711 (2005). 